\section{ALTA DIRECCIÓN PÚBLICA: CONSENSO DE REFORMA}

Por Beatriz Corbo A., Loreto Lira D., Manuel Inostroza P.

Eduardo Abarzúa

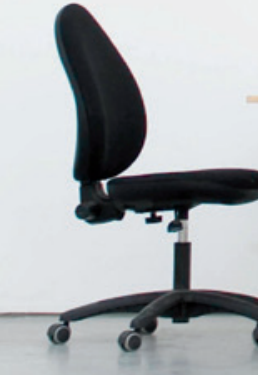

Consejeros del Consejo de Alta Dirección Pública

Hace unas semanas el gobierno envió a trámite legislativo un proyecto de ley Dirección Pública (SADP). Al respecto vale la pena interrogarse sobre la pertinencia utilidad de esta reforma.

\section{LOS LOGROS}

EI SADP ha introducido el mérito $y$ ta profesionalización como estándar de idoneidad para seleccionar directivos de los principales servicios públicos de nuestro pais. De esta manera, hay adscritos a cargos de I nivel y 839 de nivel jerárquico, que deben ser provistos a traves de concursos publicos, desarroConsejo de Alta Dirección Pública. Se ha uscado favorecer asi, la confianza de la ciudadanía en la gestión del Estado, ase- gurando el acceso y el trato igualitario para quienes participen de este proceso. En doce años de vigencia del sistema se
han recibido más de 300 mil postulaciones han recibido más de 300 mil postulaciones 100 postulaciones por concurso (en prola mujer en cargos directivos (en comparación con el sector privado) EI SADP se ha ampliado a nuevos servicios y a otras rectivos del Consejo para la Transparencia; tales, directores de Codelco; directivos de Instituto Nacional de Derechos Humanos; Panel Técnico de Concesiones de Obras Publicas y para el Comité de Auditoría eleción de 3 goo directores de establecimientos educacionales municipalizados, instituciones del Estado, seleccionando dijueces tributarios y aduaneros y ambien-

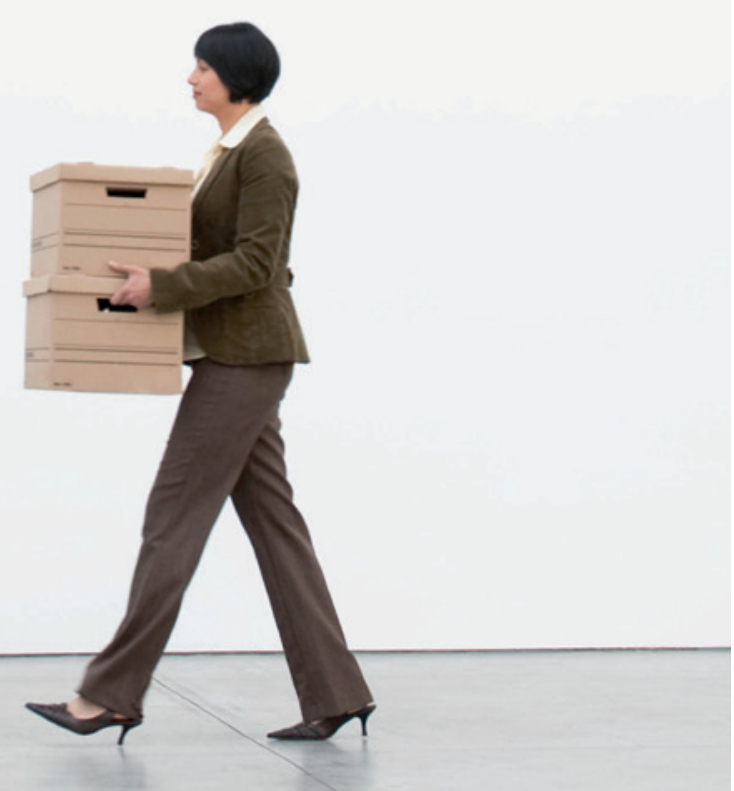

más de 300 comunas del pais. Nuestro ADP es parte de la fortaleza instituciona Yue distingue a Chile a nivel internaciona Mundiat I BID y otras instituciones.

\section{OS PENDIENTES}

Sin embargo, algunos aspectos del SADP requieren ser revisados pues generan condiciones que limitan la plena vigencia y contribución de esta política pública. Por na parte, los Altos Directivos Públicos (ADP) son de exclusiva confianza de la autoridad politica que los designa, es decir pueden ser desvinculados sin expresión de causa. Por lo mismo, las desvinculaciones sho constimen un incumplimiento legal, sich mite. Sumado a ha aplicado hasta el II- la renuncia de un $A D P$, existe la posibilidad de nombrar un directivo transitorio y proal concurso para ser titular, generando mensaje contradictorio respecto del acceso igualitario al concurso y de su trans-

Así los directivos seleccionados por e sistema no trascienden los cambios de coalición: durante el primer año del gorenuncia no voluntari al $63 \%$ de los ADPs de primer nivel jerárquico y al $24 \%$ de los de segundo nivel; el gobierno de la Presidenta Bachelet desvinculó en forma no voluntaria, en el mismo periodo, al 63 \% de los ADPs de I nivel y al 42\% del II nive. Como se ve, estos dos factores: la posibilidad de desvincular sin restricción y posibilidad de que postule quien ocupa un cargo transitoriamente mientras se concursa, se han combinado generando un efecto que amenaza las bases del sistema: la confianza ciudadana en el servicio publico, la posibilidad de atraer a los mejores directivos para gestionar el Estado y consionales para Chile.

LA REFORMA PROPUESTA

El proyecto de ley recién presentado es un aporte para mejorar y proyectar sistema, recoge aportes del Consejo y de iniciativas legislativas anteriores. Al respecto, vale la pena destacar algunas de sus propuestas:

- Elimina la posibilidad de nombrar directivos transitorios y provisionales (TyP) $y$, cuando se produzca una vacante. La función la debera ejercer el subrogante legal o algún ADP de segundo nivel del

- Faculta al Presidente de la República, - Faculta al Presidente de la República, do presidencial para que designe directamente a los directivos de hasta quince instituciones que sean prioritarias para su programa de gobierno, cumpliendo con los requisitos legales y los perfiles correspondientes. De esta manera, se construye un mejor equilibrio entre la gobernabilidad y el mérito.

- Impide concursar cargos de ADP vacantes en los ultimos cinco meses de un toridad lo solicite y el Consejo de Alta integrantes.

- Instala un sistema de gestión y un banco de candidatos que permitirá agilzar las postulaciones, incorporando antes de la etapa de entrevistas, a quienes hadirectivos públicos seleccionados por sistema que se hayan desempeñado en cargo por al menos dos añosy su desemño esté sobre el 90\%.

- Permite a los funcionarios de planta, en caso de ganar un concurso, conservar la titularidad de su cargo para la primera vez que sea nombrado como ADP, incluyendo sus renovaciones.

UNA VENTANA DE OPORTUNIDAD

Como se aprecia el proyecto de ley pefectemas claves que efectivamente perfeccionan el sistema. Un cambio de ley do, por ello se pueden formular algun

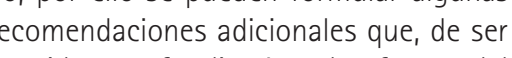
ogidas, profundizarian el esfuerzo del ejecutivo. A contizuación exponemos las Consejo de Alta Dirección Pública. - Instalar como principio que el ámbiservicios públicos. Permitiendo el ingreso instituciones como el Comité de Inversiones Extranjeras, la Superintendencia de . tras. De ser asi serian sólo tres los servicios excluidos: el Consejo de Defensa del Estado, la Direción de Presupuesto y la Agencia Nacional de Inteligencia. Y quedarian como servicios mixtos (o aquellos en que solo se adscribe ellinive).CORF, Servicio Civil.

Cropone fortalecer el un periodo ínicoño, estableciendo revisión. Haciendo obligatoria y no cultativa la publicación de los mismos $y$, estableciendo incentivos económicos según rango de cumplimiento. Asimismo, en caso que una autoridad no enve el Convenio suscrito, se sugiere faculter a la Dirección Nacional del Servicio Civ para que remita dicho incumplimiento venio de Desempeño prolonga la lógica meritocrática que se aplica al momento de seleccionar, al
función directiva.

- Vincular al Ministro lo el subsecretario delegado por ell como superior jerarquico del primer nivel. Asi la máxima autoridad queda responsabilizada, por ejemplo, de Cefinición del perfili, de la suscripción de comvenios de Desempeño, asegurando peño del ADP.

mientos del convenio de desempeño en el perfil De esta manera se contribuye a clarificar lo que la autoridad espera de quien asuma el cargo, lo que orienta a los postulantes y facilita la elaboración del convenio de desempeño, importante herramienta de gestión directiva. - Extender el pago de indemnización por desvinculación al ADP al primer año de ejrcio $y_{\text {, }}$ cear una indemnización por reDuncia voluntarila presentada durante los 3 pista mas meses de un nuevo gobierno. De en caso de ne hace legrtima la renuncia nueva administración.

- Prohibir para el Il nivel jerárquico, un nuevo gobierno, asi se incentiva la evaluación de su desempeño con el Convenio que será el instrumento disponible.

- Cuando ocurra el desistimiento de un candidato después de enviada la nómina se sugiere permitir la posibilidad de comso, según orden de puntaje.

- En el caso de renuncia de Altos Directivos Públicos, se propone permitir que autoridad nombre, a otro de los postulante que integro la nómina, en un plazo máximo El sistema de Alta Divich Publica contribuido a A Alta Dircción Publica ha Dersons en et Estado y debiese expendirse hacia otros sectores de la administración pública, permeando por ejemplo, cargos claves de la gestión municipal y regional (en un escenario de descentralización), también podría aportar en la selección de los directores de las empresas públicas. Sin embargo, la posibilidad que el sistema se expand requiere de una revisión integral del diseño institucional de los nuevos espacios de aplcación, solo asi el sistema de ADP podrá ser una aporte eficaz en una modernización integral de la gestión pública 